\title{
Neurogenesis-based epigenetic therapeutics for Alzheimer's disease (Review)
}

\author{
XUEYUAN LI, XINJIE BAO and RENZHI WANG \\ Department of Neurosurgery, Peking Union Medical College Hospital, \\ Chinese Academy of Medical Sciences and Peking Union Medical College, Beijing 100005, P.R. China
}

Received June 18, 2015; Accepted April 14, 2016

DOI: $10.3892 / \mathrm{mmr} .2016 .5390$

\begin{abstract}
Alzheimer's disease (AD) is a worldwide health problem with multiple pathogenic causes including aging, and genetic and environmental factors. As the interfaces between genes and the environment, epigenetic mechanisms, including DNA methylation, histone modification and microRNAs, are also involved in the pathogenesis of AD. Neurogenesis occurs throughout life in the normal adult brain of mammals. The neurogenic process, consisting of the proliferation, differentiation and maturation of neural stem cells (NSC), is regulated via epigenetic mechanisms by controlling the expression of specific sets of genes. In the pathology of AD, due to impairments in epigenetic mechanisms, the generation of neurons from NSCs is damaged, which exacerbates the loss of neurons and the deficits in learning and memory function associated with AD. Based on neurogenesis, a number of therapeutic strategies have shown capability in promoting neuronal generation to compensate for the neurons lost in AD, thereby improving cognitive function through epigenetic modifications. This provides potential for the treatment of $\mathrm{AD}$ by stimulating neurogenesis using epigenetic strategies. The present review discusses the epigenetics of AD and adult neurogenesis, and summarizes the neurogenesis-based epigenetic therapies targeted at AD. Such a review may offer information for the guidance of future developments of therapeutic strategies for AD.
\end{abstract}

\section{Contents}

1. Introduction

2. Epigenetics in AD

Correspondence to: Dr Renzhi Wang, Department of Neurosurgery, Peking Union Medical College Hospital, Chinese Academy of Medical Sciences and Peking Union Medical College, 5 Dongdan Santiao, Dongcheng, Beijing 100005, P.R. China

E-mail: wangrenzhipumch@163.com

Key words: Alzheimer's disease, epigenetics, neurogenesis, therapeutics
3. Epigenetics in neurogenesis

4. Neurogenesis in AD

5. Conclusions

\section{Introduction}

Alzheimer's disease (AD) is a worldwide health problem, which has a complicated pathogenesis involving diet, aging, and genetic and environmental causes (1). As the interfaces between genes and the environment, epigenetic mechanisms, which include DNA methylation, histone modification and microRNAs (miRNAs) are also implicated in the pathogenesis of AD (2). Experimental evidence has shown that the epigenetic mechanisms are altered in AD pathology, including the DNA methylation of AD-associated genes, which may promote the accumulation of $\beta$-amyloid $(A \beta)$ in plaques, intracellular formation of neurofibrillary tangles (NFTs), as well as loss of neurons, which result in dementia (3). A number of therapeutic strategies have been shown to alleviate the cognitive and memory impairments caused by AD through epigenetic modification. Thus, AD-associated epigenetics are of particular interest in investigations of the pathogenesis of $\mathrm{AD}$ and therapeutic options (4).

Neurogenesis is considered to occur throughout life within the brain of adult mammals, including humans; it contributes thousands of new neurons each day to the hippocampus to assist in the maintenance of normal cognition and memory function in humans $(5,6)$. Neurogenic processes include the proliferation, fate specification, maturation and final integration of neural stem cells (NSCs) into the existing neural circuitry; this process is regulated by intracellular programs and extracellular niche signals. Epigenetic mechanisms may be involved in the regulation of neurogenesis by translating extracellular niche signals into long-lasting changes in gene expression. In AD, neurogenesis-associated epigenetic mechanisms are altered due to changes of intracellular programs and surrounding microenvironments of NSCs (7). These include the hypermethylation of neurogenesis genes, histone de-acetylation and miRNA dysfunctions, which halt or delay NSC generation. As a consequence, the generation of neurons from neurogenesis are significantly reduced, exacerbating the loss of neurons due to AD and thereby accelerating the disease process (8-10). 
Based on neurogenesis, a number of therapeutic strategies have been designed to modify the altered epigenetic mechanisms in AD pathology (11). For example, histone deacetylase (HDAC) inhibitors, including valproic acid (VPA), have been shown to promote neuronal generation through histone modification with cognitive improvement in experiments on animals, which offers potential for the treatment of AD through epigenetic modifications (12). However, epigenetic mechanisms are complex as a regulatory system, and no epigenetic drugs have been successfully applied for the treatment of patients with AD. In the present review, the neurogenesis-based epigenetic therapies for AD were examined, with the aim of providing novel insight for future therapy development. To improve understanding of the underlying molecular mechanisms, the epigenetic changes associated with $\mathrm{AD}$ and neurogenesis were first discussed. The review may provide novel insights for the development of strategies to treat $\mathrm{AD}$ in the future.

\section{Epigenetics in AD}

Epigenetics is used to describe heritable changes in the patterns of gene expression without alterations to DNA sequences, generally including DNA methylation, histone modifications and miRNA regulation. $\mathrm{AD}$, as the most common type of dementia, is considered to arise from the formation of $A \beta$ in plaques and NFTs (13). Although this hypothesis may, in part, explain the formation of $A \beta$ and NFTs, the exact pathophysiology of AD remains to be fully elucidated. Emerging evidence has shown that epigenetic mechanisms and their changes are involved in the pathogenesis of AD.

$D N A$ methylation in $A D$. As one of the most common epigenetic mechanisms, DNA methylation adds a methyl group to the 5-position of the pyrimidine ring of the DNA base, cytosine, leading to the production of 5-methylcytosine (5-mC). DNA methylation primarily occurs in $\mathrm{CpG}$-rich sites and usually results in gene silencing; this process can be reversed by DNA methyltransferases (Dnmts). In investigations of AD, DNA methylation is the most widely examined, predominantly on the promoter methylation of known AD genes, particularly for APP. Duplication of the APP gene increases the risk of AD through gene overexpression, and epigenetic changes of $A P P$ promoters can also enhance gene expression and the susceptibility to AD. However, existing reports of DNA methylation in $\mathrm{AD}$ are controversial; with reports of hypomethylation of APP promoters in patients with AD relative to controls (14), others reporting hypermethylation (15) and others reporting no significant AD-associated abnormalities (16). These may be associated with differences in the brain regions assessed across the studies (17), however, it is more likely due to the drift and diversity in epigenetic modifications, rather than specific methylation changes, which occur at APP promoters (18). This view point is supported by several other studies showing that the levels of 5-mc and Dnmt3a are increased in the hippocampus of aging mice, but were reduced in APP/PS1 transgenic mice, and in the hippocampus, enthorhinal cortex and cerebellum of patients with AD $(19,20)$.

In addition to $A P P$, no significant differences have been observed in the methylation of microtubule-associated protein tau $(M A P T), G S K 3 B$ and PSEN1 promoters in the frontal cortex and the hippocampus in patients with $\mathrm{AD}$ and controls, even at different stages of AD (16). However, certain genes are affected by DNA methylation in AD. The S100A2 genes, which encode a calcium binding protein, have been found to be hypomethylated in $\mathrm{AD}$, with a resulting increase in gene expression to promote corpora amylacea formation (21). By contrast, NEP genes, which encode a protease controlling $\mathrm{A} \beta$ degradation, and SORBS3 genes, which encode a cell adhesion molecule, are hypermethylated (22). The reduced gene expression levels of $N E P$ and $S O R B S 3160$ contribute to A $\beta$ deposition and synaptic disturbances, respectively $(23,24)$. In addition, the methylation levels of the MAPT gene are higher in the aged human hippocampus and cerebral cortex, compared with those in young individuals $(15,25)$. Based on these findings, it is possible that the disturbances in DNA methylation are implicated in AD pathogenesis. However, the functional impacts of AD-associated DNA methylation remain to be fully elucidated.

Histone modifications in AD. Histone modification is another important epigenetic mechanism, which modifies DNA and includes acetylation, methylation, phosphorylation, ubiquitination and isomerization. These modifications can alter the accessibility of DNA to transcription regulators by inducing changes to the structural configuration of nucleosomes. Alterations in histone acetylation have been reported in studies of AD. The levels of histone $\mathrm{H} 3$ and histone $\mathrm{H} 4$ acetylation were significantly increased in AD brain tissues post-mortem, compared with those in age-matched controls (26). Increased histone $\mathrm{H} 3$ acetylation is considered to be due to disruptions in its homeostasis, induced by soluble $\mathrm{A} \beta$, in $\mathrm{AD}$ pathology (27), and it is associated with increased levels of $\beta$-secretase 1 (BACE1), a protease that cleaves APP in the amyloidogenic pathway (28). Abnormal histone $\mathrm{H} 4$ acetylation leads to differential gene expression, and is associated with impaired learning and memory functions in AD-associated insults $(2,29)$. In addition, non-nuclear histone $\mathrm{H} 1$ has been reported to be upregulated in the neurons and astrocytes of brain regions susceptible to $\mathrm{AD}(30)$.

Histone acetylation is a dynamic reversible process, which is regulated by histone acetyltransferases (HATs) and histone deacetylases (HDACs). HDAC2 is an important regulator for memory and synaptic plasticity, and has been shown to be disturbed in AD-associated process (31). In AD mice, a significant increase in the expression levels of HDAC2 were detected in the hippocampus and prefrontal cortex of the mice, however, no notable changes in the expression of HDAC2 were observed in the amygdala, an area not affected by AD (32). These findings are supported by other observations showing aberrant histone acetylation levels in patients with AD (32). Notably, increased levels of HDAC2 and hypoacetylation have been found to negatively correlate with the mRNA expression levels of genes associated with learning, memory and synaptic plasticity (32). By contrast, the inhibition of HDAC2 reinstates the structural and synaptic plasticity, eliminating the AD-associated memory impairments (32). These findings suggest that the levels of HDAC2 are significantly enhanced in the AD-affected brain regions, and disruption of HDAC2 activity can increase the development of AD. 
miRNAs in AD. miRNAs, a broad class of small non-coding RNAs involved in gene post-transcriptional control, constitute another important epigenetic mechanism. By binding to the 3'-untranslated regions (3'-UTR) of messenger RNAs (mRNAs), miRNAs can inhibit the translation of target mRNAs. The dysregulation of miRNAs has been demonstrated to be implicated in the pathophysiology of AD. As noted above, the increased expression of APP leads to enhanced A $\beta$ production, and consequently to AD pathogenesis. In parallel, miRNA-mediated regulation of the expression of APP has been investigated extensively in order to elucidate relevant mechanisms underlying $\mathrm{AD}(33,34)$. As a result, a number of miRNAs have been shown to be associated with APP metabolism and $\mathrm{A} \beta$ production, including miR let-7, miR-16, miR-101, miR-106b, miR-124, miR-137, miR-153, miR-181, miR-644 and miR-645 (35-38). Specifically, miR-124 is able to alter the splicing of APP exons 7 and 8 in neuronal cells by repressing the polypyrimidine tract binding protein 1 (PTBP1) transcript, the level of which has been found to be reduced in a subset of patients with $A D$ (39), indicating that the miR-124/PTBPl pathway is important for APP splicing in neurons. Simultaneously, miR-124 has been shown to regulate the expression of $B A C E 1$, which correlates with A $\beta$-induced cell death (40). The inhibition or overexpression of miR-124 may upregulate or downregulate the expression of BACE1. miR-16 has also been found to target APP to potentially modulate AD-associated pathogenesis in mice. The increased expression of miR-16 leads to decrease in the protein expression of APP (41). In addition, miR-106b, which is negatively correlated with the expression of APP, has been found to be significantly reduced in patients with sporadic AD (42).

Disruption in the expression of tau also implicates miRNA in the pathology of AD. For example, miR-15, miR-16, miR-26b, miR-34a, miR-125b, miR-132 and miR-497 have been linked to aberrant tau regulation, of which miR-132 has been shown to regulate the alterative splicing of tau exon 10 through repression of $P T B P 2$ transcription (43). The repression of $P T B P 2$ transcription interferes with the physiological phosphorylation of tau and thus leads to the dysfunction of miR-132 to a disease state. Of note, the overexpression of miR-132 has been found to reduce the protein levels of APP in the brains of senescence-accelerated mouse prone 8 (SAMP8), however, reduced expression of miR-132 causes APP protein accumulation in AD mice (41). Aberrant expression of miR-16 is also of vital importance for the pathogenesis of $\mathrm{AD}$, with the overexpression of miR-16 leading to NFT formation and a decrease in its expression leading to APP protein accumulation (41). miR-26b, another epigenetic regulator of the expression of tau, has been found to arise in the substantia nigra at an early stage of AD stage, and is maintained at a high level in the brain areas exhibiting AD pathology during disease progression. miR-26b targets the mRNA of Retinoblastoma ( $\mathrm{Rb})$, and its overexpression downregulates the expression of $\mathrm{Rb}$. The overexpression of miR-26b and downregulation of Rb enhances tau phosphorylation and aggregation, followed by neuronal apoptosis and neurodegeneration (44). In addition, overexpressed miR-125b has been found to induce tau hyperphosphorylation and cognitive deficits in $\mathrm{AD}$ mice through upregulation in the levels of p35, cdk5 and p44/42-MAPK signaling, and downregulation of the USP6 and PPPICA phosphatases, and anti-apoptotic factor, B cell lymphoma $(\mathrm{Bcl})-\mathrm{W}$, suggesting the involvement of miR-125 in the pathogenesis of AD (45).

Microenvironmental epigenetics in $A D$. The epigenetics of microenvironments are also affected by changes in the pathology of AD. Studies have shown that the expression of the growth arrest and DNA-damage inducible 45 (Gadd45) family protein, which has been identified as a vital mediator of the DNA demethylation process (46), is upregulated at the early stage of AD (47), but decreased at the late stage of the disease (48). Although the early upregulation of Gadd45 suggests DNA damage in AD (47), its late decrease indicates impairment of intracellular pathways involved in sensing and repairing DNA damage (48). The disrupted expression of Gadd45 may be associated with aberrant APP processing, as $A \beta 1-42$ and $A \beta 25-35$ have been shown to provoke an early and marked increase in the level of Gadd45 in cultured human neurons (49). Methyl-CpG-binding protein 2 (MeCP2), another important epigenetic regulator in the extracellular microenvironment, has also been found to be significantly reduced in in vivo and in vitro studies of $\mathrm{AD}(50,51)$. The reduction of $\mathrm{MeCP} 2$ may be caused by $\mathrm{A} \beta$-induced neuroinflammation and may lead to notable defects in the production of brain-derived neurotrophic factor (BDNF), axonal transport, synaptic efficacy and neuronal maturation in AD (52-54).

AD-associated neuropathology can also induce changes in microenvironmental epigenetics. $A \beta$ has been reported to affect aberrant $\mathrm{CpG}$ methylation in $A P P, N E P$ and $M A P T$ genes of the AD brain, with resulting $A P P$ and $M A P T$ dysfunction, which is important for the pathogenesis and progression of $\mathrm{AD}(55,56)$. Of note, the presence of a small number of highly methylated neurons among normal neurons has been found to contribute to the methylation differences in APP and MAPT CpGs (56). Chronic inflammation is involved in neurodegenerative diseases, including AD (57), which correlates with the promoter hypermethylation of synaptophysin and BDNF, and the hypomethylation of BCL-2-associated X protein, which are important for neuronal maintenance $(58,59)$. In addition, oxidative stress occurs in AD, which can induce the hypermethylation of genes associated with neuronal and synaptic plasticity (60). Hypermethylated genes appear to be more vulnerable to toxic effects caused by $A \beta$, further increasing oxidative stress-induced damage to DNA (61). Oxidative stress may also, through epigenetic changes, activate certain gene pathways, which are hyperactive in $\mathrm{AD}$, including those associated with inflammations (3).

\section{Epigenetics in neurogenesis}

Neurogenesis occurs throughout life within the mammalian adult brain, which generates thousands of new neurons to assist in the maintenance of normal cognition and memory function. Neurogenesis is regulated by multiple epigenetic mechanisms, including DNA methylation, histone acetylation and miRNAs. As the interface between genes and the environment, epigenetic mechanisms can translate environmental signals into gene expression levels within NSCs. The extracellular microenvironment may also be involved in the regulation of neurogenesis via epigenetic mechanisms. 
Neurogenesis in adults. Neurogenesis persists throughout life in two brain regions of adult mammals: The subventricular zone (SVZ) and the subgranular zone (SGZ). Neurogenic processes include the proliferation, migration, differentiation, maturation and functional integration of NSCs into the local brain network $(11,62)$. In SVZ, NSCs are relatively quiescent radial glia-like cells, which divide infrequently to produce fast-dividing precursor cells (NPCs). NPCs act as intermediate cell types, which generate neuroblasts $(63,64)$, the majority of which move along the rostral migratory stream to the olfactory bulb where they largely differentiate into GABAergic neurons (65). In SGZ, primary NSCs also have low proliferative activity and classical astrocytic features. These cells can give rise to two types of transit-amplifying neuroblasts, which can migrate into the dentate granule cell layer of hippocampus in which they differentiate into glutamatergic neurons and integrate into the local circuitry (66). It is estimated that neurogenesis contributes thousands of new neurons each day to the hippocampus in adult mammals (67), which benefits the maintenance of normal cognitive and learning function $(68,69)$.

NSCs reside in a highly specialized microenvironment, termed a 'niche', which is composed of structural cells, extracellular matrix proteins, microvasculature and soluble factors (70). The niche has an important effect on neurogenesis, and can protect NSC populations from differentiation stimuli and apoptotic signals in a stable balance with proliferation (71). It has been shown that NSCs can proliferate and differentiate into neurons when transplanted into neurogenic niches (72), whereas NSCs destined for the neuronal lineage can switch to glial differentiation when transplanted into non-neurogenic regions (73). In addition, neural precursors have been isolated from the spinal cord, white matter, entorhinal cortex, amygdala and striatum of adult mammalian brains, which have traditionally been considered to be non-neurogenic $(6,74)$. These precursors can generate neurons following transplantation back to neurogenic regions of the adult brain (72). In addition, several types of brain injury, including ischemia and seizures, have been shown to promote the proliferation, migration and differentiation of precursors in non-neurogenic regions $(5,75)$. All the above data indicate that multi-potent precursors exist in non-neurogenic regions, their proliferative capacity is limited by local microenvironments, and that injury or disease can rescue neurogenesis by inducing microenvironmental changes.

DNA methylation in neurogenesis. Specific attention has been paid to the performance of DNA methylation and Dnmts in neurogenesis. Cultured neurospheres have been observed to exhibit DNA methylation, and the expression of Dnmt1 and Dnmt3a (72). Upon cell differentiation and migration, the expression levels of Dnmt1 and Dnmt3a are severely decreased in NSCs, whereas DNA methylation has been found to increase and decrease in these differentiating/migrating cells at different loci (72). If methylation is inhibited, NSC differentiation and migration are markedly reduced (76). These observations suggest that, in addition to changes of DNA methylation following decreases in Dnmts, the repression of stem cell maintenance genes and combined activation of cell differentiation genes occurs in the active NSCs $(70,77)$. In further studies of DNMT3a in neuronal differentiation, it has been found that DNMT3a is expressed in the SVZ and SGZ in postnatal mice (78), whereas NSC differentiation is markedly decreased in DNMT3a-knockout mice (79). Epigenetic analysis has shown that, in addition to the downregulation of neurogenic genes, the genes associated with glial differentiation are upregulated in Dnmt3a-knockout mice (80), suggesting that Dnmt3a may serve as an important regulator, switching gene expression towards either a neuronal or non-neuronal lineage.

The regulation of neurogenesis induced by DNA methylation is modulated by methyl- $\mathrm{CpG}$ binding proteins (MBDs). MBD1 is primarily expressed in adult neurons, which can repress the expression of genes encoding fibroblast factors by binding to the promoters (81). The expression of MBD1 is lowered in undifferentiated NSCs, increased at the initiation of their differentiation, and promptly decreased at the onset of migration (82). When MBD1 is inhibited, neurogenesis is significantly reduced, accompanied by an increase in new astrocytes (83). These findings suggest that MBD1 is involved in the maintenance and differentiation of adult NSCs. As another member of the MBDs, MeCP2 shares a similar mechanism with MBD1 in regulating gene expression. It has been found that MeCP2 is expressed at high levels in mature neurons of the adult mouse hippocampus, but absent in oligodendrocytes and astrocytes (7). When MeCP2-expressing neural progenitors are transplanted into non-neurogenic regions, notable neuronal differentiation is observed (84). By contrast, impaired neuronal maturation characterized by decreases in dendritic spine formation and spine density has been detected in MeCP2-knockout mice (53). It appears that $\mathrm{MeCP} 2$ is important in multiple stages of neurogenesis, including the maturation, differentiation and fate determination of NSCs (85).

Histone modification in neurogenesis. Histone modification can mediate neurogenesis at various stages by controlling gene expression. Studies have shown that HAT-mediated histone acetylation can increase the proliferation and differentiation of NSCs (86), whereas HDACs-induced de-acetylation has more important effects on neurogenesis. HDAC3, HDAC5 and HDAC7 have been shown to be expressed simultaneously in undifferentiated NSCs from adult mice, the expression levels of which are decreased at the start of differentiation (87). When HDACs are inhibitors with inhibitors, including VPA, NSC proliferation is markedly reduced, particularly for cells of a glial lineage, however, neuronal progression is increases, even with the presence of factors favoring non-neuronal differentiation (88). Further analysis has shown high levels of $\mathrm{H} 3$ and $\mathrm{H} 4$ acetylation in undifferentiated NSCs, and lower levels of $\mathrm{H} 3$ and $\mathrm{H} 4$ acetylation in stem cells progressing to astrocytes and oligodendrocytes $(89,90)$. However, their levels have been shown to increase upon the differentiation of NSCs into neurons in VPA-treated cells. These findings suggest that HDAC activity is crucial for the proliferation and fate determination of NSCs, in which histone acetylation maintenance is required for neuronal progression, and its de-acetylation is necessary for glial differentiation.

HDAC2, another member of the HDAC family, appears to be more important in the maturation of adult NSCs. HDAC2 is specifically expressed in dividing cells in the adult SVZ and SGZ (91). The depletion of HDAC2 in mice induces a notable 
increase of transit-amplifying cells, however, these fail to progress into mature neurons. This increased but impaired neuronal generation in HDAC2-deficient mice may be associated with the lack of HDAC2-induced gene repression, which may upregulate transcription activators, including SRY-box 2 (Sox2), promoting NSC proliferation, but damaging their maturation capacity (92). These results indicate that HDAC2 activity is important for NSC proliferation, and that sufficient histone de-acetylation is required for neuronal maturation.

Histone methylation is also involved in the regulation of adult neurogenesis (93), which is a process mediated by two antagonistic chromatin complexes of the polycomb and trithorax group ( $\mathrm{PcG}$ and $\mathrm{TrxG}$ ) proteins, which can activate or silence their target genes, respectively (94). The PcG complex promotes histone 3 lysine 27 tri-methylation (H3K27me3), whereas the TrxG protein enhances histone 3 lysine 4 tri-methylation (H3K4me3). B lymphoma Mo-MLV insertion region 1 homolog $(\mathrm{Bmi}-\mathrm{l})$ is a typical member of the PcG complexes, acting as a key epigenetic regulator in neurogenesis (95). It has been shown that the overexpression of Bmi-l markedly increases the number of adult NSCs in the SVZ, and also improves their developmental capacity to neuronal lineages in vitro and in vivo $(96,97)$. When Bmi-l is knocked down, the self-renew ability of NSCs is severely impaired (98). The action of Bmi-1 may be associated with repression of the expression of cell cycle inhibitors of p16 and p19 (99) or interaction with the transcription factor, Foxg1, which is important for NSC multipotency and self-renewal maintenance (100). Studies have also reported that the $\mathrm{PcG}$ complex promotes NSC self-renew by silencing genes required for differentiation through PcG-mediated H3K27 tri-methylation (101-103).

In contrast to the PcG complex, TrxG proteins predominantly contribute to the neural progression between NSCs and neuronal phenotypes, with mixed-lineage leukemia 1 (M111) as an example (104). The distal-less homeobox 2 (Dlx2) protein is a key target of Mll1 and serves as a crucial regulator for adult neurogenesis in the SVZ. Studies have shown that SVZ Mll1-deficient NSCs survive, proliferate and efficiently progress into glial lineages without neuronal differentiation, however, the overexpression of Dlx 2 has been observed to rescue neurogenesis in these cells $(104,105)$. Previous chromatin immunoprecipitation analysis showed that Mll1 bound directly to the Dlx2 promoter, and a high level of H3K4 trimethylation was observed in a wide range of differentiating NSCs. By contrast, chromatin at Dlx 2 was markedly bivalent by $\mathrm{H} 3 \mathrm{~K} 4$ and $\mathrm{H} 3 \mathrm{~K} 27$ trimethylation in Mll1-deficient SVZ cells (104). It appears that the bivalent histone methylation leads to failure of the Dlx gene to activate normally, and M111 recruits $\mathrm{H} 3 \mathrm{~K} 27$ demethylase to resolve the silenced bivalent loci in SVZ NSCs for neuronal, but not glial, differentiation $(104,106)$. This finding is supported by another previous study which showed that Jmjd3, an H3K27 demethylase, can activate the neurogenic program, which ensures the progression of NSCs along a neuronal pathway (107). Thus, PcG- and TrxG-dependent histone methylation are required for adult neurogenesis, and the expression of Mll-1 may assist in maintaining NSC neuronal fate without glial conversion.

miRNAs in neurogenesis. A number of miRNAs have been identified at different stages of NSC generation, and different
miRNAs perform different functions at different developmental stages. In addition, these miRNAs constitute complex regulatory networks with transcription factors and chromatin modifiers. For example, miR-184, a direct target of MBD1, has been demonstrated to promote NSC proliferation, but inhibit NSC differentiation $(108,109)$, whereas the inhibition of miR-184 rescues the phenotypes in MBD1 deficiency (Liu, et al 2010), suggesting its importance in modulating NSC self-renew. Mechanical analysis has shown that miR-184, which can be directly repressed by MBD1, regulates the expression of Numblike (Numbl), a known regulator of neuronal differentiation during development, by binding to the 3'-UTR of Numbl mRNA and affecting its translation (108). By contrast, restoration of the expression of endogenous Numbl rescues the defects in NSCs resulting from either the overexpression of miR-184 or MBD1 deficiency (108). From these observations, it appears that MBD1, miR-184 and Numbl form an interaction network with miR-184 as a central modulator, controlling the balance between the proliferation and differentiation of NSCs.

miR-124, as one of the most abundant miRNAs, is crucial for neural differentiation from stem cells in the adult SVZ. Studies have shown that miR-124 is distinctively expressed in neuroblast cells, and its level increases until the cell cycle exit of neuroblasts $(70,110)$. The knockdown of miR-124 maintains purified SVZ NSCs as dividing NPCs, however, the ectopic expression of miR-124 leass to precocious and increased neuron formation (110), indicating that the expression of miR-124 is important for the transition of adult NSCs between transit-amplifying cells and neuroblasts. In subsequent functional studies, miR-124 has been found to interact with the transcription factor, Sox9, the expression of which can specifically commit neural progenitors to glial fate via the Notch signaling pathway $(110,111)$. The expression of miR-124 induces downregulation of the Sox 9 protein in NSCs, leading to the correction of cell state differentiation towards neuronal fates (110). Thus, miR-124-induced post-transcriptional repression of Sox 9 is crucial for progression of SVZ NSCs along the neuronal lineage.

miR-137 is specifically expressed in adult neurons and has been shown to be involved in the process of neuronal maturation $(112,113)$. Whereas the overexpression of miR-137 inhibits dendritic morphogenesis, phenotypic maturation and spine development in the brain and cultured primary neurons, the repression of miR-137 produces the opposite effects (104). Further studies have shown that miR-137 targets the mind bomb 1 protein, a ubiquitin ligase important in neurodevelopment (112), and miR-137 represses the translation of Ech2, a histone methyltransferase and $\mathrm{PcG}$ protein, leading to a global reduction of H3K27me3 in adult SGZ NSCs (105). In addition, miR-137 is epigenetically regulated by MeCP2 and Sox-2, which are important for neuronal differentiation and maturation (113). It appears that miR-137, MeCP and PcG form a cross-talk loop, which modulates the bivalent H3K27 levels at specific gene domains and thus affects gene expression. In contrast to miR-137, miR-132 promotes neuronal maturation by promoting dendritic morphogenesis, spine density, synaptic integration and the survival of newborn neurons (114) through post-transcriptional repression of the expression of nuclear receptor related 1 (115) and reducing repressor element-1 silencing transcription factor (116). 
Microenvironmental epigenetics in neurogenesis. The extracellular microenvironment in which the NSCs reside changes with aging, brain trauma, stroke and seizures, and is also involved in the regulation of neurogenesis through epigenetic mechanisms. Whereas NSCs and their progeny directly adapt to environmental changes, microenvironmental cells, including mature neurons, can mobilize their own epigenetic mechanisms to translate environmental signals into long-lasting gene modifications. In addition, microenvironmental cells can regulate neurogenesis by establishing cross-talk with NSCs in their epigenetic mechanisms $(117,118)$.

The Gadd45 family proteins can respond to microenvironmental changes by repressing specific genes through the promotion of DNA demethylation within their promoters (70). Gadd45b is an activity-induced immediate early gene, specifically expressed in mature dentate granule neurons in the SGZ, and its transcription is particularly sensitive to transient stimulation (46). The expression of Gadd45b induced by neuronal activity can promote DNA demethylation in several genes important for neurogenesis, including those encoding BDNF and fibroblast growth factor (FGF), which can stably increase adult neurogenesis (101). The importance of Gadd45b in neurogenesis is underlined in studies of transgenic mice lacking Gadd45b, which showed that the increase in neuronal proliferation of neural progenitors and the dendritic growth of newborn neurons following electroconvulsive therapy were notably decreased in the Gadd45b-deficient mice (46). Methylation analysis has shown that Gadd45b is essential for the demethylation of several genes associated with neurogenesis, including FGF1 (119). These findings suggest that Gadd45b functions as a sensor for microenviromental signals in mature neurons, and the neuronal activity-induced expression of Gadd45b may regulate adult neurogenesis through epigenetic DNA modifications.

$\mathrm{MeCP} 2$, also abundant in mature dentate granule neurons, is another important mediator, which regulates the expression of BDNF in an activity-dependent manner (120,121). By adjusting the DNA methylation status of activity-dependent genes (101), MeCP2 is involved in the regulation of neuronal maturation $(46,122)$. Although the extent to which MeCP2 impacts neuronal maturation remains to be fully elucidated, marked defects in the maturation of neurons, including delayed differentiation and reduced dendritic spine density, have been noted in the SGZ of MeCP2-knockout mice (123). Similar to DNA methylation, histone modifications can be dynamically mediated through the activity-dependent regulations of chromatin remodeling and modifying enzymes, including HATs and HDACs in mature neurons (124-126). In addition, several miRNAs, including miR-138, have been found to integrate environmental changes in the regulation of neurogenic processes $(113,127,128)$.

As important microenvironmental cells, endothelial and glial cells are also involved in the regulation of adult neurogenesis in the SGZ and SVZ. In addition to providing structural supports for neurogenesis (1), these cells can interact with NSCs via cross-talk, mediated by cytokines, including endothelial cell growth factor and glial-derived nerve factor (GDNF), which can activate multiple signal pathways and increase NSC proliferation through epigenetic mechanisms (129). There are also several inducible positive feed-back signal loops between NSCs and cells in the microenvironment mediated by cytokines, which ensures the homeostasis and balance between these two groups of cells $(130,131)$. In addition, several signaling molecules have demonstrated involvement in different stages of neurogenesis $(132,133)$. From these results, it appears that microenvironmental epigenetics is involved in the regulation of neurogenesis and may be used as a therapeutic target for regulating adult neurogenesis.

\section{Neurogenesis in AD}

As stated above, epigenetic mechanisms are altered in AD, and neurogenesis is regulated by epigenetic mechanisms. Due to altered epigenetic mechanisms in the pathology of $\mathrm{AD}$, the neurogenesis considered to persist throughout life in the mammalian brain is impaired, which contributes to the loss of neurons and deficits in learning and memory. Neurogenic impairment and associated epigenetic therapies have been investigated intensively in studies of AD.

Neurogenic impairment in $A D$. Increasing evidence has shown that the disease symptoms of AD may be partly be attributed to the impaired formation of neurons from NSCs in the SGZ and SVZ, which is important for the maintenance of normal learning and memory function (134). The epigenetic mechanisms altered in AD may cause direct impairments to neurogenesis. As discussed above, DNA methylation, which is crucial for NSC proliferation, differentiation and migration, is disrupted in AD pathology, with resulting neurogenic impairment (8). In the SVZ of AD mice, increased histone $\mathrm{H} 3$ acetylation significantly reduces cell proliferation throughout life (9). Deregulation in the expression of miRNAs lead to a decrease in the expression of growth factors, including BDNF, and thus impair synaptic plasticity and neurogenesis in AD (10). Oxidative stress and inflammation can also lead to dysfunction in neurogenesis via multiple epigenetic alterations (135-137).

Neurogenic impairment in AD can also be caused by epigenetic alterations associated with the formation of $A \beta$ plaques and NFTs. The dysfunction of DNA methylation in the APP, PSEN1 and tau promoters can cause overexpression of these genes and lead to the excessive production of $A \beta$ and phosphorylated tau proteins. Although the impacts of $A \beta s$ on neurogenesis remain controversial, $\mathrm{A} \beta$ plaques and NFTs can cause severe damage to neurons (138) and astrocytes (139), leading to a gradual loss of neurons responsible for AD symptoms. As a result, the reduction in neuronal numbers and activity decrease the function of Gadd45b and MeCP2, promotes the demethylation of neurogenic genes, including FGF1 and BDNF (119), and finally impairs neurogenesis. Damaged astrocytes not only abate the structural supports for neurogenesis, but also reduce the expression of nerve growth factors (NGFs), including GDNF. In addition, certain subtypes of $A \beta$ proteins, including $A \beta 25-35$, has been shown to be toxic to neurogenesis (1), and tau aggregation can lead to neurodegeneration and neuronal death (140). Based on these findings, it can be concluded that neurogenesis is impaired in AD due to epigenetic dysfunctions, which provide opportunities for therapeutic intervention. 
Neurogenesis-based epigenetic therapies for AD. Based on neurogenesis, a number of epigenetic therapies have been developed in the treatment of AD. Notably, HDAC inhibitors, which can increase histone acetylation by inhibiting histone deacetylation, have been suggested as potential treatments for AD, of which VPA has been shown to reduce NSC proliferation, induce the differentiation of neural progenitors specifically towards a neuronal lineage, and inhibit progression to an astrocyte or oligodendrocyte fate (141). In animal models of AD, VPA has been reported to improve learning and memory deficits by promoting NSC generation and synaptic development $(12,34)$. VPA has also been found to increase the protein levels of NGF in the hippocampus of transgenic AD mice, correlating with cognitive improvement (142). In addition, ercaptoacetamide-based class II HDAC inhibitors have been shown to lower levels of $\mathrm{A} \beta$, and to improve learning and memory in a mouse model of AD (143). In addition, $\gamma$-hydroxybutyrate has been found to induce HDAC inhibition and the gene expression of neprilysin, to reduce the levels of $\mathrm{A} \beta$ and simultaneously ameliorate clinical symptoms in AD mice (144). Gallic acid, an HDAC inhibitor, has also been demonstrated to suppress $A \beta$ neurotoxicity by inhibiting microglial-mediated neuroinflammation (145).

Compared with HDAC inhibitors, a number of drugs, which are specifically designed at DNA methylation, exhibit neurogenic effects in the treatment of AD. For example, S-adenosylmethionine and 1-methylfolate, which provide methyl groups in the body to enhance DNA methylation $(4,146)$, have been found to improve the learning and cognitive performance associated with AD (147-149). In other studies, S-adenosylmethionine and 1-methylfolate have been used as adjunctive therapies for combating AD $(148,149)$, and these therapies have been shown to enhance the expression of genes associated with neurogenesis more than those associated with apoptosis (150). Fortunately, a number of these treatments, including as 1-methylfolate, have been used as an adjuvant therapy in the treatment and prevention of patients with a high risk of AD $(151,152)$.

Several miRNA regulators have also been developed for treating AD. For example, the injection of AM206, a neutralizing inhibitor of miR-206, into the cerebral ventricles of AD mice has been shown to increase the brain levels of BDNF and improve memory function (10). In parallel, AM206 enhances hippocampal neurogenesis and synaptic density. By using RNA interference, the knockdown of long-form phosphodiesterase-4D, using a lentiviral RNA construct containing a specific miRNA, increased the level of BDNF in the hippocampus and reversed the memory impairment caused by $\mathrm{A} \beta$ in mice (153). miR-34c, which is essential for normal brain development (154), has also been recognized as a therapeutic target for treating $\mathrm{AD}$, as miR-34c is elevated in the hippocampus of patients with AD and AD mouse models, and targeting the miR-34c seed rescues learning ability in these mouse models (155).

To date, no drugs have been designed to specifically target the epigenetic alterations of the microenvironments in AD. However, certain therapeutic strategies have been shown to enhance the expression of genes associated with neurogenesis in the treatment of $\mathrm{AD}$, indicating the modification of epigenetic mechanisms (156-158). For example, granulocyte colony stimulating factor has been found to induce neurogenesis, reduce oxidative stress and the levels of acetylcholinesterase, and increase antioxidant enzymes and total RNA expression levels in rat AD models, which is followed by improvements in memory and neurobehavioral function (159). Similar observations have been made in AD animals treated with neurotrophic peptide and IGF2 (156-158). It may be that these therapies attenuate the epigenetic alterations of the microenvironments by alleviating inflammation and oxidative stress in the brain in $\mathrm{AD}(160)$.

\section{Conclusions}

As discussed, significant advances have been made in the understanding of epigenetics in AD and neurogenesis, and in investigations of neurogenesis-based epigenetic therapies for the treatment of $\mathrm{AD}$. In $\mathrm{AD}$, epigenetic mechanisms are altered due to neurodegenerative conditions, which include the dysfunction of DNA methylation, histone acetylation and miRNA regulation. Neurogenesis exists in the normal adult mammalian brain and contributes to the maintenance of normal brain function. The neurogenic process is regulated by multiple epigenetic mechanisms. Epigenetic dysfunctions due to AD impair the formation of neurons from NSCs, which contributes to the loss of neurons and cognitive impairment. Restoration of the epigenetics altered in AD can enhance neurogenesis, which provides novel promise for combating this disease. A number of epigenetic therapies have been shown to alleviate cognitive impairments by promoting neurogenesis in preclinical studies. However, understanding of epigenetic regulations in neurogenesis remains at an early stage, particularly in the field of $\mathrm{AD}$, and further investigations are required. It is anticipated that targeting the epigenetic modifications of adult neurogenesis as a potential therapy may ultimately become feasible in patients with $\mathrm{AD}$ in future.

\section{Acknowledgements}

This review was supported by the National High Technology Research and Development Program ('973' and '863' Programs; grant nos. 2014CB541603 and 2013AA020106, respectively) of China, and the National Natural Science Foundation of China (grant nos. 81301061 and 81200916).

\section{References}

1. Li XY, Bao XJ and Wang RZ: Potential of neural stem cell-based therapies for Alzheimer's disease. J Neurosci Res 93: 1313-1324, 2015.

2. Graff J, Kim D, Dobbin MM and Tsai LH: Epigenetic regulation of gene expression in physiological and pathological brain processes. Physiol Rev 91: 603-649, 2011.

3. Zawia NH, Lahiri DK and Cardozo-Pelaez F: Epigenetics, oxidative stress, and Alzheimer disease. Free Radic Biol Med 46: 1241-1249, 2009.

4. Day JJ and Sweatt JD: Epigenetic treatments for cognitive impairments. Neuropsychopharmacology 37: 247-260, 2012.

5. Emsley JG, Mitchell BD, Kempermann G and Macklis JD: Adult neurogenesis and repair of the adult CNS with neural progenitors, precursors, and stem cells. Prog Neurobiol 75: 321-341, 2005.

6. Ernst A, Alkass K, Bernard S, Salehpour M, Perl S, Tisdale J, Possnert G, Druid H and Frisén J: Neurogenesis in the striatum of the adult human brain. Cell 156: 1072-1083, 2014. 
7. Kohyama J, Kojima T, Takatsuka E, Yamashita T, Namiki J, Hsieh J, Gage FH, Namihira M, Okano H, Sawamoto K and Nakashima K: Epigenetic regulation of neural cell differentiation plasticity in the adult mammalian brain. Proc Natl Acad Sci USA 105: 18012-18017, 2008.

8. Taher N, McKenzie C, Garrett R, Baker M, Fox N and Isaacs GD: Amyloid- $\beta$ alters the DNA methylation status of cell-fate genes in an Alzheimer's disease model. J Alzheimers Dis 38: 831-844, 2014.

9. Rodriguez JJ, Jones VC and Verkhratsky A: Impaired cell proliferation in the subventricular zone in an Alzheimer's disease model. Neuroreport 20: 907-912, 2009.

10. Lee ST, Chu K, Jung KH, Kim JH, Huh JY, Yoon H, Park DK, Lim JY, Kim JM, Jeon D, et al: miR-206 regulates brain-derived neurotrophic factor in Alzheimer disease model. Ann Neurol 72: 269-277, 2012.

11. Jordan JD, Ming GL and Song H: Adult neurogenesis as a potential therapy for neurodegenerative diseases. Discov Med 6: 144-147, 2006

12. Qing H, He G, Ly PT, Fox CJ, Staufenbiel M, Cai F, Zhang Z, Wei S, Sun X, Chen CH, et al: Valproic acid inhibits Abeta production, neuritic plaque formation, and behavioral deficits in Alzheimer's disease mouse models. J Exp Med 205: 2781-2789, 2008

13. Li X, Bao X and Wang R: Experimental models of Alzheimer's disease for deciphering the pathogenesis and therapeutic screening (Review). Int J Mol Med 37: 271-283, 2016 (Review).

14. West RL, Lee JM and Maroun LE: Hypomethylation of the amyloid precursor protein gene in the brain of an Alzheimer's disease patient. J Mol Neurosci 6: 141-146, 1995.

15. Tohgi H, Utsugisawa K, Nagane Y, Yoshimura M, Genda $Y$ and Ukitsu M: Reduction with age in methylcytosine in the promoter region -224 approximately -101 of the amyloid precursor protein gene in autopsy human cortex. Brain Res Mol Brain Res 70: 288-292, 1999

16. Barrachina M and Ferrer I: DNA methylation of Alzheimer disease and tauopathy-related genes in postmortem brain J Neuropathol Exp Neurol 68: 880-891, 2009.

17. Ladd-Acosta C, Pevsner J, Sabunciyan S, Yolken RH Webster MJ, Dinkins T, Callinan PA, Fan JB, Potash JB and Feinberg AP: DNA methylation signatures within the human brain. Am J Hum Genet 81: 1304-1315, 2007.

18. Wang SC, Oelze B and Schumacher A: Age-specific epigenetic drift in late-onset Alzheimer's disease. PloS One 3: e2698, 2008.

19. Chouliaras L, Mastroeni D, Delvaux E, Grover A, Kenis G, Hof PR, Steinbusch HW, Coleman PD, Rutten BP and van den Hove DL: Consistent decrease in global DNA methylation and hydroxymethylation in the hippocampus of Alzheimer's disease patients. Neurobiol Aging 34: 2091-2099, 2013

20. Condliffe D, Wong A, Troakes C, Proitsi P, Patel Y, Chouliaras L, Fernandes C, Cooper J, Lovestone S, Schalkwyk L, et al: Cross-region reduction in 5-hydroxymethylcytosine in Alzheimer's disease brain. Neurobiol Aging 35: 1850-1854, 2014

21. Hoyaux D, Decaestecker C, Heizmann CW, Vogl T, Schäfer BW Salmon I, Kiss R and Pochet R: S100 proteins in corpora amylacea from normal human brain. Brain Res 867: 280-288, 2000.

22. Iraola-Guzmán S, Estivill $X$ and Rabionet R: DNA methylation in neurodegenerative disorders: A missing link between genome and environment? Clin Genet 80: 1-14, 2011

23. Urdinguio RG, Sanchez-Mut JV and Esteller M: Epigenetic mechanisms in neurological diseases: Genes, syndromes and therapies. Lancet Neurol 8: 1056-1072, 2009.

24. Wang S, Wang R, Chen L, Bennett DA, Dickson DW and Wang DS: Expression and functional profiling of neprilysin, insulin-degrading enzyme, and endothelin-converting enzyme in prospectively studied elderly and Alzheimer's brain. J Neurochem 115: 47-57, 2010.

25. Sanchez-Mut JV, Aso E, Heyn H, Matsuda T, Bock C, Ferrer I and Esteller M: Promoter hypermethylation of the phosphatase DUSP22 mediates PKA-dependent TAU phosphorylation and CREB activation in Alzheimer's disease. Hippocampus 24: 363-368, 2014

26. Narayan PJ, Lill C, Faull R, Curtis MA and Dragunow M: Increased acetyl and total histone levels in post-mortem Alzheimer's disease brain. Neurobiol Dis 74: 281-294, 2015.

27. Lithner CU, Lacor PN, Zhao WQ, Mustafiz T, Klein WL, Sweatt JD and Hernandez CM: Disruption of neocortical histone H3 homeostasis by soluble A $\beta$ : Implications for Alzheimer's disease. Neurobiol Aging 34: 2081-2090, 2013.
28. Zhang K, Schrag M, Crofton A, Trivedi R, Vinters H and Kirsch W: Targeted proteomics for quantification of histone acetylation in Alzheimer's disease. Proteomics 12: 1261-1268, 2012.

29. Peleg S, Sananbenesi F, Zovoilis A, Burkhardt S, Bahari-Javan S, Agis-Balboa RC, Cota P, Wittnam JL, Gogol-Doering A, Opitz L, et al: Altered histone acetylation is associated with age-dependent memory impairment in mice. Science 328: 753-756, 2010

30. Kanai Y, Akatsu $\mathrm{H}$, Iizuka $\mathrm{H}$ and Morimoto C: Could serum antibody to poly(ADP-ribose) and/or histone $\mathrm{H} 1$ be marker for senile dementia of Alzheimer type? Ann NY Acad Sci 1109: 338-344, 2007.

31. Chouliaras L, van den Hove DL, Kenis G, Draanen Mv, Hof PR, van Os J, Steinbusch HW, Schmitz C and Rutten BP. Histone deacetylase 2 in the mouse hippocampus: Attenuation of age-related increase by caloric restriction. Curr Alzheimer Res 10: 868-876, 2013.

32. Graff J, Rei D, Guan JS, Wang WY, Seo J, Hennig KM, Nieland TJ, Fass DM, Kao PF, Kahn M, et al: An epigenetic blockade of cognitive functions in the neurodegenerating brain. Nature 483: 222-226, 2012

33. Maciotta S, Meregalli $\mathrm{M}$ and Torrente $\mathrm{Y}$ : The involvement of microRNAs in neurodegenerative diseases. Front Cell Neurosci 7: 265, 2013

34. Schonrock N, Matamales M, Ittner LM and Götz J: MicroRNA networks surrounding APP and amyloid- $\beta$ metabolism-implications for Alzheimer's disease. Exp Neurol 235: 447-454, 2012.

35. Delay C,Calon F, Mathews P and Hébert SS: Alzheimer-specific variants in the 3'UTR of Amyloid precursor protein affect microRNA function. Mol Neurodegener 6: 70, 2011.

36. Long JM and Lahiri DK: MicroRNA-101 downregulates Alzheimer's amyloid- $\beta$ precursor protein levels in human cell cultures and is differentially expressed. Biochem Biophys Res Commun 404: 889-895, 2011.

37. Niwa R, Zhou F, Li C and Slack FJ: The expression of the Alzheimer's amyloid precursor protein-like gene is regulated by developmental timing microRNAs and their targets in Caenorhabditis elegans. Dev Biol 315: 418-425, 2008.

38. Rodriguez-Ortiz CJ, Baglietto-Vargas D, Martinez-Coria H, LaFerla FM and Kitazawa M: Upregulation of miR-181 decreases c-Fos and SIRT-1 in the hippocampus of 3xTg-AD mice. J Alzheimers Dis 42: 1229-1238, 2014.

39. Smith P, Al Hashimi A, Girard J, Delay C and Hébert SS: In vivo regulation of amyloid precursor protein neuronal splicing by microRNAs. J Neurochem 116: 240-247, 2011.

40. Fang M, Wang J, Zhang X, Geng Y, Hu Z, Rudd JA, Ling S, Chen W and Han S: The miR-124 regulates the expression of BACE1/ $\beta$-secretase correlated with cell death in Alzheimer's disease. Toxicol Lett 209: 94-105, 2012.

41. Liu W, Liu C, Zhu J, Shu P, Yin B, Gong Y, Qiang B, Yuan J and Peng X: MicroRNA-16 targets amyloid precursor protein to potentially modulate Alzheimer's-associated pathogenesis in SAMP8 mice. Neurobiol Aging 33: 522-534, 2012.

42. Hebert SS, Horré K, Nicolaï L, Bergmans B, Papadopoulou AS Delacourte A and De Strooper B: MicroRNA regulation of Alzheimer's amyloid precursor protein expression. Neurobiol Dis 33: 422-428, 2009.

43. Hébert SS, Sergeant N and Buée L: MicroRNAs and the regulation of tau metabolism. Int J Alzheimers Dis 2012: 406561, 2012.

44. Absalon S, Kochanek DM, Raghavan V and Krichevsky AM MiR-26b, upregulated in Alzheimer's disease, activates cell cycle entry, tau-phosphorylation, and apoptosis in postmitotic neurons. J Neurosci 33: 14645-14659, 2013.

45. Banzhaf-Strathmann J, Benito E, May S, Arzberger T, Tahirovic S, Kretzschmar H, Fischer A and Edbauer D: MicroRNA-125b induces tau hyperphosphorylation and cognitive deficits in Alzheimer's disease. EMBO J 33: 1667-1680, 2014

46. Ma DK, Jang MH, Guo JU, Kitabatake Y, Chang ML, Pow-Anpongkul N, Flavell RA, Lu B, Ming GL and Song H: Neuronal activity-induced Gadd45b promotes epigenetic DNA demethylation and adult neurogenesis. Science 323: 1074-1077, 2009.

47. Santiard-Baron D, Gosset P, Nicole A, Sinet PM, Christen Y and Ceballos-Picot I: Identification of beta-amyloid-responsive genes by RNA differential display: Early induction of a DNA damage-inducible gene, gadd45. Exp Neurol 158: 206-213, 1999. 
48. Uberti D, Carsana T, Bernardi E, Rodella L, Grigolato P, Lanni C, Racchi M, Govoni S and Memo M: Selective impairment of p53-mediated cell death in fibroblasts from sporadic Alzheimer's disease patients. J Cell Sci 115: 3131-3138, 2002 .

49. Santiard-Baron D, Lacoste A, Ellouk-Achard S, Soulié C, Nicole A, Sarasin A and Ceballos-Picot I: The amyloid peptide induces early genotoxic damage in human preneuron NT2. Mutat Res 479: 113-120, 2001

50. Bihaqi SW and Zawia NH: Alzheimer's disease biomarkers and epigenetic intermediates following exposure to $\mathrm{Pb}$ in vitro. Curr Alzheimer Res 9: 555-562, 2012.

51. Stagni F, Giacomini A, Guidi S, Ciani E, Ragazzi E, Filonzi M, De Iasio R, Rimondini R and Bartesaghi R: Long-term effects of neonatal treatment with fluoxetine on cognitive performance in Ts65Dn mice. Neurobiol Dis 74: 204-218, 2015.

52. Bie B, Wu J, Yang H, Xu JJ, Brown DL and Naguib M: Epigenetic suppression of neuroligin 1 underlies amyloid-induced memory deficiency. Nat Neurosci 17: 223-231, 2014.

53. Noutel J, Hong YK, Leu B, Kang E and Chen C Experience-dependent retinogeniculate synapse remodeling is abnormal in MeCP2-deficient mice. Neuron 70: 35-42, 2011.

54. Roux JC, Zala D, Panayotis N, Borges-Correia A, Saudou F and Villard L: Modification of Mecp2 dosage alters axonal transport through the Huntingtin/Hap1 pathway. Neurobiol Dis 45: 786-795, 2012.

55. Chen KL, Wang SS, Yang YY, Yuan RY, Chen RM and Hu CJ: The epigenetic effects of amyloid-beta(1-40) on global DNA and neprilysin genes in murine cerebral endothelial cells. Biochem Biophys Res Commun 378: 57-61, 2009.

56. Iwata A, Nagata $K$, Hatsuta $H$, Takuma H, Bundo $M$, Iwamoto K, Tamaoka A, Murayama S, Saido T and Tsuji S: Altered CpG methylation in sporadic Alzheimer's disease is associated with APP and MAPT dysregulation. Hum Mol Genet 23: 648-656, 2014

57. Wilkins HM, Carl SM, Weber SG, Ramanujan SA, Festoff BW, Linseman DA and Swerdlow RH: Mitochondrial lysates induce inflammation and Alzheimer's disease-relevant changes in microglial and neuronal cells. J Alzheimers Dis 45: 305-318, 2015.

58. Garcia I, Crowther AJ, Gama V, Miller CR, Deshmukh M and Gershon TR: Bax deficiency prolongs cerebellar neurogenesis, accelerates medulloblastoma formation and paradoxically increases both malignancy and differentiation. Oncogene 32: 2304-2314, 2013

59. Keleshian VL, Modi HR, Rapoport SI and Rao JS: Aging is associated with altered inflammatory, arachidonic acid cascade, and synaptic markers, influenced by epigenetic modifications, in the human frontal cortex. J Neurochem 125: 63-73, 2013.

60. Fleming JL, Phiel CJ and Toland AE: The role for oxidative stress in aberrant DNA methylation in Alzheimer's disease. Curr Alzheimer Res 9: 1077-1096, 2012.

61. Gu X, Sun J, Li S, Wu X and Li L: Oxidative stress induces DNA demethylation and histone acetylation in SH-SY5Y cells Potential epigenetic mechanisms in gene transcription in $\mathrm{A} \beta$ production. Neurobiol Aging 34: 1069-1079, 2013.

62. Jin K and Galvan V: Endogenous neural stem cells in the adult brain. J Neuroimmune Pharmacol 2: 236-242, 2007.

63. de Almeida Sassi F, Lunardi Brunetto A, Schwartsmann G Roesler R and Abujamra AL: Glioma revisited: From neurogenesis and cancer stem cells to the epigenetic regulation of the niche. J Oncol 2012: 537861, 2012.

64. Doetsch F, Caillé I, Lim DA, Garcia-Verdugo JM and Alvarez-Buylla A: Subventricular zone astrocytes are neural stem cells in the adult mammalian brain. Cell 97: 703-716, 1999.

65. Schaeffer EL, Novaes BA, da Silva ER, Skaf HD and Mendes-Neto AG: Strategies to promote differentiation of newborn neurons into mature functional cells in Alzheimer brain. Prog Neuropsychopharmacol Biol Psychiatry 33: 1087-1102, 2009.

66. Seri B, García-Verdugo JM, McEwen BS and Alvarez-Buylla A: Astrocytes give rise to new neurons in the adult mammalian hippocampus. J Neurosci 21: 7153-7160, 2001.

67. Garzón-Muvdi T and Quinones-Hinojosa A: Neural stem cell niches and homing: Recruitment and integration into functional tissues. ILAR J 51: 3-23, 2009.

68. Sahay A, Wilson DA and Hen R: Pattern separation: A common function for new neurons in hippocampus and olfactory bulb. Neuron 70: 582-588, 2011.
69. Shors TJ: From stem cells to grandmother cells: How neurogenesis relates to learning and memory. Cell Stem Cell 3: 253-258, 2008

70. Fitzsimons CP, van Bodegraven E, Schouten M, Lardenoije R, Kompotis K, Kenis G, van den Hurk M, Boks MP, Biojone C, Joca $\mathrm{S}$, et al: Epigenetic regulation of adult neural stem cells: Implications for Alzheimer's disease. Mol Neurodegener 9: 25, 2014.

71. Moore KA and Lemischka IR: Stem cells and their niches. Science 311: 1880-1885, 2006.

72. Shihabuddin LS, Horner PJ, Ray J and Gage FH: Adult spinal cord stem cells generate neurons after transplantation in the adult dentate gyrus. J Neurosci 20: 8727-8735, 2000.

73. Seidenfaden R, Desoeuvre A, Bosio A, Virard I and Cremer H: Glial conversion of SVZ-derived committed neuronal precursors after ectopic grafting into the adult brain. Mol Cell Neurosci 32: 187-198, 2006.

74. Siebzehnrubl FA and Steindler DA: Isolating and culturing of precursor cells from the adult human brain. Methods Mol Biol 1059: 79-86, 2013.

75. Nakatomi H, Kuriu T, Okabe S, Yamamoto S, Hatano O, Kawahara N, Tamura A, Kirino $\mathrm{T}$ and Nakafuku $\mathrm{M}$ : Regeneration of hippocampal pyramidal neurons after ischemic brain injury by recruitment of endogenous neural progenitors. Cell 110: 429-441, 2002

76. Singh RP, Shiue K, Schomberg D and Zhou FC: Cellular epigenetic modifications of neural stem cell differentiation. Cell Transplant 18: 1197-1211, 2009.

77. Yang G, Song Y, Zhou X, Deng Y, Liu T, Weng G, Yu D and Pan S: DNA methyltransferase 3, a target of microRNA-29c, contributes to neuronal proliferation by regulating the expression of brain-derived neurotrophic factor. Mol Med Rep 12: 1435-1442, 2015.

78. Wu H, Coskun V, Tao J, Xie W, Ge W, Yoshikawa K, Li E, Zhang Y and Sun YE: Dnmt3a-dependent nonpromoter DNA methylation facilitates transcription of neurogenic genes. Science 329: 444-448, 2010.

79. Challen GA, Sun D, Jeong M, Luo M, Jelinek J, Berg JS, Bock C, Vasanthakumar A, Gu H, Xi Y, et al: Dnmt3a is essential for hematopoietic stem cell differentiation. Nat Genet 44: 23-31, 2011.

80. Wu Z, Huang K, Yu J,Le T, Namihira M, Liu Y, Zhang J, Xue Z Cheng $L$ and Fan G: Dnmt3a regulates both proliferation and differentiation of mouse neural stem cells. J Neurosci Res 90: 1883-1891, 2012

81. Li X, Barkho BZ, Luo Y, Smrt RD, Santistevan NJ, Liu C, Kuwabara T, Gage FH and Zhao X: Epigenetic regulation of the stem cell mitogen Fgf-2 by Mbd1 in adult neural stem/ progenitor cells. J Biol Chem 283: 27644-27652, 2008.

82. Adefuin AM, Kimura A, Noguchi H, Nakashima K and Namihira M: Epigenetic mechanisms regulating differentiation of neural stem/precursor cells. Epigenomics 6: 637-649, 2014.

83. Zhao X, Ueba T, Christie BR, Barkho B, McConnell MJ, Nakashima K, Lein ES, Eadie BD, Willhoite AR, Muotri AR, et al: Mice lacking methyl-CpG binding protein 1 have deficits in adult neurogenesis and hippocampal function. Proc Natl Acad Sci USA 100: 6777-6782, 2003.

84. Tsujimura K, Abematsu M, Kohyama J, Namihira M and Nakashima K: Neuronal differentiation of neural precursor cells is promoted by the methyl-CpG-binding protein MeCP2 Exp Neurol 219: 104-111, 2009

85. Kishi N and Macklis JD: MeCP2 functions largely cell-autonomously, but also non-cell-autonomously, in neuronal maturation and dendritic arborization of cortical pyramidal neurons. Exp Neurol 222: 51-58, 2010.

86. Johnson AA, Sarthi J, Pirooznia SK, Reube W and Elefant F: Increasing Tip60 HAT levels rescues axonal transport defects and associated behavioral phenotypes in a Drosophila Alzheimer's disease model. J Neurosci 33: 7535-7547, 2013.

87. Sharma R, Ottenhof T, Rzeczkowska PA and Niles LP Epigenetic targets for melatonin: Induction of histone $\mathrm{H} 3$ hyperacetylation and gene expression in C17.2 neural stem cells. J Pineal Res 45: 277-284, 2008.

88. Dozawa M, Kono $\mathrm{H}$, Sato $\mathrm{Y}$, Ito $\mathrm{Y}$, Tanaka $\mathrm{H}$ and Ohshima T: Valproic acid, a histone deacetylase inhibitor, regulates cell proliferation in the adult zebrafish optic tectum. Dev Dyn 243: 1401-1415, 2014.

89. Huang HY, Liu DD, Chang HF, Chen WF, Hsu HR, Kuo JS and Wang MJ: Histone deacetylase inhibition mediates urocortin-induced antiproliferation and neuronal differentiation in neural stem cells. Stem Cells 30: 2760-2773, 2012. 
90. Liu H, Wu H, Wang Y, Wang Y, Wu X, Ju S and Wang X: Inhibition of class II histone deacetylase blocks proliferation and promotes neuronal differentiation of the embryonic rat neural progenitor cells. Acta Neurobiol Exp (Wars) 72: 365-376, 2012

91. Jawerka M, Colak D, Dimou L, Spiller C, Lagger S, Montgomery RL, Olson EN, Wurst W, Göttlicher M and Götz M: The specific role of histone deacetylase 2 in adult neurogenesis. Neuron Glia Biol 6: 93-107, 2010.

92. Foti SB, Chou A, Moll AD and Roskams AJ: HDAC inhibitors dysregulate neural stem cell activity in the postnatal mouse brain. Int J Dev Neurosci 31: 434-447, 2013.

93. Foret MR, Sandstrom RS, Rhodes CT, Wang Y, Berger MS and Lin $\mathrm{CH}$ : Molecular targets of chromatin repressive mark $\mathrm{H} 3 \mathrm{~K} 9 \mathrm{me} 3$ in primate progenitor cells within adult neurogenic niches. Front Genet 5: 252, 2014

94. Contestabile A and Sintoni S: Histone acetylation in neurodevelopment. Curr Pharm Des 19: 5043-5050, 2013.

95. Acquati S, Greco A, Licastro D, Bhagat H, Ceric D, Rossini Z, Grieve J, Shaked-Rabi M, Henriquez NV, Brandner S, et al: Epigenetic regulation of survivin by Bmil is cell type specific during corticogenesis and in gliomas. Stem Cells 31: 190-202, 2013.

96. Chatoo W, Abdouh M, Duparc RH and Bernier G: Bmil distinguishes immature retinal progenitor/stem cells from the main progenitor cell population and is required for normal retinal development. Stem Cells 28: 1412-1423, 2010.

97. He S, Iwashita T, Buchstaller J, Molofsky AV, Thomas D and Morrison SJ: Bmi-1 over-expression in neural stem/progenitor cells increases proliferation and neurogenesis in culture but has little effect on these functions in vivo. Dev Biol 328: 257-272, 2009.

98. Zencak D, Lingbeek M, Kostic C, Tekaya M, Tanger E, Hornfeld D, Jaquet M, Munier FL, Schorderet DF, van Lohuizen M and Arsenijevic Y: Bmil loss produces an increase in astroglial cells and a decrease in neural stem cell population and proliferation. J Neurosci 25: 5774-5783, 2005.

99. Molofsky AV, He S, Bydon M, Morrison SJ and Pardal R Bmi-1 promotes neural stem cell self-renewal and neural development but not mouse growth and survival by repressing the p16Ink4a and p19Arf senescence pathways. Genes Dev 19: $1432-1437,2005$

100. Fasano CA, Phoenix TN, Kokovay E, Lowry N, Elkabetz Y, Dimos JT, Lemischka IR, Studer L and Temple S: Bmi-1 cooperates with Foxg1 to maintain neural stem cell self-renewal in the forebrain. Genes Dev 23: 561-574, 2009.

101. Ma DK, Marchetto MC, Guo JU, Ming GL, Gage FH and Song H: Epigenetic choreographers of neurogenesis in the adult mammalian brain. Nat Neurosci 13: 1338-1344, 2010.

102. Pasini D, Malatesta M, Jung HR, Walfridsson J, Willer A Olsson L, Skotte J, Wutz A, Porse B, Jensen ON and Helin K Characterization of an antagonistic switch between histone $\mathrm{H} 3$ lysine 27 methylation and acetylation in the transcriptional regulation of Polycomb group target genes. Nucleic Acids Res 38: 4958-4969, 2010

103. Fouse SD, Shen Y, Pellegrini M, et al.: Promoter CpG methylation contributes to ES cell gene regulation in parallel with Oct4/Nanog, PcG complex, and histone H3 K4/K27 trimethylation. Cell Stem Cell 2: 160-169, 2008.

104. Lim DA, Huang YC, Swigut T, Mirick AL, Garcia-Verdugo JM Wysocka J, Ernst P and Alvarez-Buylla A: Chromatin remodelling factor M111 is essential for neurogenesis from postnatal neural stem cells. Nature 458: 529-533, 2009.

105. Potts MB, Siu JJ, Price JD, Salinas RD, Cho MJ, Ramos AD, Hahn J, Margeta M, Oldham MC and Lim DA: Analysis of M111 deficiency identifies neurogenic transcriptional modules and Brn4 as a factor for direct astrocyte-to-neuron reprogramming. Neurosurgery 75: 472-482, 2014

106. Steffen PA, Fonseca JP, Gänger C, Dworschak E, Kockmann T, Beisel C and Ringrose L: Quantitative in vivo analysis of chromatin binding of Polycomb and Trithorax group proteins reveals retention of ASH1 on mitotic chromatin. Nucleic Acids Res 41: 5235-5250, 2013.

107. Jepsen K, Solum D, Zhou T, McEvilly RJ, Kim HJ, Glass CK, Hermanson O and Rosenfeld MG: SMRT-mediated repression of an $\mathrm{H} 3 \mathrm{~K} 27$ demethylase in progression from neural stem cell to neuron. Nature 450: 415-419, 2007.

108. Liu C, Teng ZQ, Santistevan NJ, Szulwach KE, Guo W, Jin P and Zhao X: Epigenetic regulation of miR-184 by MBD1 governs neural stem cell proliferation and differentiation. Cell Stem Cell 6: 433-444, 2010.
109. Shalom-Feuerstein R, Serror L, De La Forest Divonne S, Petit I, Aberdam E, Camargo L, Damour O, Vigouroux C, Solomon A, Gaggioli C, et al: Pluripotent stem cell model reveals essential roles for miR-450b-5p and miR-184 in embryonic corneal lineage specification. Stem Cells 30: 898-909, 2012.

110. Cheng LC, Pastrana E, Tavazoie M and Doetsch F: miR-124 regulates adult neurogenesis in the subventricular zone stem cell niche. Nature Neurosci 12: 399-408, 2009.

111. Martini S, Bernoth K, Main H, Ortega GD, Lendahl U, Just U and Schwanbeck R: A critical role for Sox9 in notch-induced astrogliogenesis and stem cell maintenance. Stem Cells 31: 741-751, 2013.

112. Smrt RD, Szulwach KE, Pfeiffer RL, Li X, Guo W, Pathania M Teng ZQ, Luo Y, Peng J, Bordey A, et al: MicroRNA miR-137 regulates neuronal maturation by targeting ubiquitin ligase mind bomb-1. Stem Cells 28: 1060-1070, 2010.

113. Szulwach KE,Li X, SmrtRD, Li Y, Luo Y,Lin L, Santistevan NJ, Li W, Zhao X and Jin P: Cross talk between microRNA and epigenetic regulation in adult neurogenesis. J Cell Biol 189: 127-141, 2010.

114. Pathania M, Torres-Reveron J, Yan L, Kimura T, Lin TV, Gordon V, Teng ZQ, Zhao X, Fulga TA, Van Vactor D and Bordey A: miR-132 enhances dendritic morphogenesis, spine density, synaptic integration and survival of newborn olfactory bulb neurons. PloS One 7: e38174, 2012

115. Yang D, Li T, Wang Y, Tang Y, Cui H, Tang Y, Zhang X, Chen D, Shen $\mathrm{N}$ and Le W: miR-132 regulates the differentiation of dopamine neurons by directly targeting Nurrl expression. J Cell Sci 125: 1673-1682, 2012.

116. Remenyi J, Hunter CJ, Cole C, Ando H, Impey S, Monk CE Martin KJ, Barton GJ, Hutvagner G and Arthur JS: Regulation of the miR-212/132 locus by MSK1 and CREB in response to neurotrophins. Biochem J 428: 281-291, 2010.

117. Imamura $T$, Uesaka $M$ and Nakashima K: Epigenetic setting and reprogramming for neural cell fate determination and differentiation. Philos Trans R Soc Lond B Biol Sci 369: 20130511, 2014.

118. Shin Y, Yang K, Han S, Park HJ, Seok Heo Y, Cho SW and Chung S: Reconstituting vascular microenvironment of neural stem cell niche in three-dimensional extracellular matrix. Adv Healthc Mater 3: 1457-1464, 2014.

119. Mohamed Ariff I, Mitra A and Basu A: Epigenetic regulation of self-renewal and fate determination in neural stem cells. J Neurosci Res 90: 529-539, 2012.

120. Degano AL, Park MJ, Penati J, Li Q and Ronnett GV: MeCP2 is required for activity-dependent refinement of olfactory circuits. Mol Cell Neurosci 59: 63-75, 2014.

121. Zhou Z, Hong EJ, Cohen S, Zhao WN, Ho HY, Schmidt L, Chen WG, Lin Y, Savner E, Griffith EC, et al: Brain-specific phosphorylation of $\mathrm{MeCP} 2$ regulates activity-dependent Bdnf transcription, dendritic growth, and spine maturation. Neuron 52: 255-269, 2006.

122. Feng J, Zhou Y, Campbell SL, Le T, Li E, Sweatt JD, Silva AJ and Fan G: Dnmt1 and Dnmt3a maintain DNA methylation and regulate synaptic function in adult forebrain neurons. Nat Neurosci 13: 423-430, 2010.

123. Abuhatzira L, Makedonski K, Kaufman Y, Razin A and Shemer R: MeCP2 deficiency in the brain decreases BDNF levels by REST/CoREST-mediated repression and increases TRKB production. Epigenetics 2: 214-222, 2007.

124. Chen M, Takano-Maruyama M, Pereira-Smith OM, Gaufo GO and Tominaga K: MRG15, a component of HAT and HDAC complexes, is essential for proliferation and differentiation of neural precursor cells. J Neurosci Res 87: 1522-1531, 2009.

125. Park HG, Yu HS, Park S, Ahn YM, Kim YS and Kim SH: Repeated treatment with electroconvulsive seizures induces HDAC2 expression and down-regulation of NMDA receptor-related genes through histone deacetylation in the rat frontal cortex. Int J Neuropsychopharmacol 17: 1487-1500, 2014.

126. Kuzumaki N, Ikegami D, Tamura R, Hareyama N, Imai S, Narita M, Torigoe K, Niikura K, Takeshima H, Ando T, et al: Hippocampal epigenetic modification at the brain-derived neurotrophic factor gene induced by an enriched environment. Hippocampus 21: 127-132, 2011.

127. Follert $\mathrm{P}$, Cremer $\mathrm{H}$ and Béclin $\mathrm{C}$ : MicroRNAs in brain development and function: A matter of flexibility and stability. Front Mol Neurosci 7: 5, 2014.

128. Kisliouk T, Cramer T and Meiri N: Heat stress attenuates new cell generation in the hypothalamus: A role for miR-138. Neuroscience 277: 624-636, 2014. 
129. Liu Q, Fan X, Zhu J, Xu G, Li Y and Liu X: Co-culturing improves the OGD-injured neuron repairing and NSCs differentiation via notch pathway activation. Neurosci Lett 559: 1-6, 2014.

130. Li Q, Ford MC, Lavik EB and Madri JA: Modeling the neurovascular niche: VEGF- and BDNF-mediated cross-talk between neural stem cells and endothelial cells: An in vitro study. J Neurosci Res 84: 1656-1668, 2006.

131. Young A, Assey KS, Sturkie CD, West FD, Machacek DW and Stice SL: Glial cell line-derived neurotrophic factor enhances in vitro differentiation of mid-/hindbrain neural progenitor cells to dopaminergic-like neurons. J Neurosci Res 88: 3222-3232, 2010.

132. Gómez-Gaviro MV, Scott CE, Sesay AK, Matheu A, Booth S, Galichet $\mathrm{C}$ and Lovell-Badge R: Betacellulin promotes cell proliferation in the neural stem cell niche and stimulates neurogenesis. Proc Natl Acad Sci USA 109: 1317-1322, 2012.

133. Stolp HB and Molnár Z: Neurogenic niches in the brain: Help and hindrance of the barrier systems. Front Neurosci 9: 20, 2015.

134. Zhao C, Deng W and Gage FH: Mechanisms and functional implications of adult neurogenesis. Cell 132: 645-660, 2008.

135. Bewernick BH and Schlaepfer TE: Chronic depression as a model disease for cerebral aging. Dialogues Clin Neurosci 15: 77-85, 2013.

136. Bufill E, Blesa R and Augustí J: Alzheimer's disease: An evolutionary approach. J Anthropol Sci 91: 135-157, 2013.

137. Hamilton A and Holscher C: The effect of ageing on neurogenesis and oxidative stress in the APP(swe)/PS1(deltaE9) mouse model of Alzheimer's disease. Brain Res 1449: 83-93, 2012.

138. Walsh K, Megyesi J and Hammond R: Human central nervous system tissue culture: A historical review and examination of recent advances. Neurobiol Dis 18: 2-18, 2005.

139. Abramov AY, Canevari L and Duchen MR: Changes in intracellular calcium and glutathione in astrocytes as the primary mechanism of amyloid neurotoxicity. J Neurosci 23: 5088-5095, 2003.

140. Schindowski K, Belarbi K, Bretteville A, Ando K and Buée L: Neurogenesis and cell cycle-reactivated neuronal death during pathogenic tau aggregation. Genes Brain Behav 7 (Suppl 1): S92-S100, 2008

141. Hsieh J, Nakashima K, Kuwabara T, Mejia E and Gage FH: Histone deacetylase inhibition-mediated neuronal differentiation of multipotent adult neural progenitor cells. Proc Natl Acad Sci USA 101: 16659-16664, 2004.

142. Noh H and Seo H: Age-dependent effects of valproic acid in Alzheimer's disease (AD) mice are associated with nerve growth factor (NGF) regulation. Neuroscience 266: 255-265, 2014.

143. Sung YM, Lee T, Yoon H, DiBattista AM, Song JM, Sohn Y, Moffat EI, Turner RS, Jung M, Kim J and Hoe HS: Mercaptoacetamide-based class II HDAC inhibitor lowers A $\beta$ levels and improves learning and memory in a mouse model of Alzheimer's disease. Exp Neurol 239: 192-201, 2013.

144. Klein C, Mathis C, Leva G, Patte-Mensah C, Cassel JC, Maitre $M$ and Mensah-Nyagan AG: $\gamma$-Hydroxybutyrate (Xyrem) ameliorates clinical symptoms and neuropathology in a mouse model of Alzheimer's disease. Neurobiol Aging 36: $832-844,2015$

145. Kim MJ, Seong AR, Yoo JY, Jin CH, Lee YH, Kim YJ, Lee J, Jun WJ and Yoon HG: Gallic acid, a histone acetyltransferase inhibitor, suppresses $\beta$-amyloid neurotoxicity by inhibiting microglial-mediated neuroinflammation. Mol Nutr Food Res 55: 1798-1808, 2011.
146. Peedicayil J: Role of epigenetics in pharmacotherapy, psychotherapy and nutritional management of mental disorders. J Clin Pharm Ther 37: 499-501, 2012.

147. Montgomery SE, Sepehry AA, Wangsgaard JD and Koenig JE: The effect of S-adenosylmethionine on cognitive performance in mice: An animal model meta-analysis. PloS One 9: e107756, 2014.

148. Papakostas GI, Cassiello CF and Iovieno N: Folates and S-adenosylmethionine for major depressive disorder. Can J Psychiatry 57: 406-413, 2012.

149. Papakostas GI, Shelton RC, Zajecka JM, Etemad B, Rickels K, Clain A, Baer L, Dalton ED, Sacco GR, Schoenfeld D, et al: L-methylfolate as adjunctive therapy for SSRI-resistant major depression: Results of two randomized, double-blind, parallel-sequential trials. Am J Psychiatry 169: 1267-1274, 2012

150. Zhang J, Li P, Wang Y, Liu J, Zhang Z, Cheng W and Wang Y: Ameliorative effects of a combination of baicalin, jasminoidin and cholic acid on ibotenic acid-induced dementia model in rats. PloS One 8: e56658, 2013.

151. Fava M, Shelton RC and Zajecka JM: Evidence for the use of 1-methylfolate combined with antidepressants in MDD. J Clin Psychiatry 72: e25, 2011.

152. McCaddon A and Hudson PR: L-methylfolate, methylcobalamin, and $\mathrm{N}$-acetylcysteine in the treatment of Alzheimer's disease-related cognitive decline. CNS Spectr 15 (Suppl 1): S2-S5, 2010; discussion 6, 2010.

153. Zhang C, Cheng Y, Wang H, Wang C, Wilson SP, Xu J and Zhang HT: RNA interference-mediated knockdown of long-form phosphodiesterase-4D (PDE4D) enzyme reverses amyloid- $\beta 42$-induced memory deficits in mice. J Alzheimers Dis 38: 269-280, 2014.

154. Wu J, Bao J, Kim M, Yuan S, Tang C, Zheng H, Mastick GS, $\mathrm{Xu} \mathrm{C}$ and Yan W: Two miRNA clusters, miR-34b/c and miR-449, are essential for normal brain development, motile ciliogenesis, and spermatogenesis. Proc Natl Acad Sci USA 111: E2851-E2857, 2014.

155. Zovoilis A, Agbemenyah HY, Agis-Balboa RC, Stilling RM, Edbauer D, Rao P, Farinelli L, Delalle I, Schmitt A, Falkai P, et al: microRNA-34c is a novel target to treat dementias. EMBO J 30: 4299-4308, 2011.

156. Bolognin S, Blanchard J, Wang X, Basurto-Islas G, Tung YC, Kohlbrenner E, Grundke-Iqbal I and Iqbal K: An experimental rat model of sporadic Alzheimer's disease and rescue of cognitive impairment with a neurotrophic peptide. Acta Neuropathol 123: 133-151, 2012.

157. Kazim SF, Blanchard J, Dai CL, Tung YC, LaFerla FM, Iqbal IG and Iqbal K: Disease modifying effect of chronic oral treatment with a neurotrophic peptidergic compound in a triple transgenic mouse model of Alzheimer's disease. Neurobiol Dis 71: $110-130,2014$.

158. Mellott TJ, Pender SM, Burke RM, Langley EA and Blusztajn JK: IGF2 ameliorates amyloidosis, increases cholinergic marker expression and raises BMP9 and neurotrophin levels in the hippocampus of the APPswePS1dE9 Alzheimer's disease model mice. PloS One 9: e94287, 2014

159. Prakash A, Medhi B and Chopra K: Granulocyte colony stimulating factor (GCSF) improves memory and neurobehavior in an amyloid- $\beta$ induced experimental model of Alzheimer's disease. Pharmacol Biochem Behav 110: 46-57, 2013.

160. Jiang P, Li C, Xiang Z and Jiao B: Tanshinone IIA reduces the risk of Alzheimer's disease by inhibiting iNOS, MMP2 and NF- $\mathrm{KBp} 65$ transcription and translation in the temporal lobes of rat models of Alzheimer's disease. Mol Med Rep 10: 689-694, 2014 